\title{
Light-Induced Spin Crossover in an Fe(II) Low-Spin Complex Enabled by Surface Adsorption
}

\author{
Sebastian Rohlf, ${ }^{\dagger}$ Manuel Gruber, ${ }^{*} \dagger$ Benedikt Flöser, ${ }^{\ddagger}$ Jan Grunwald ${ }^{\ddagger}$ Simon \\ Jarausch, ${ }^{\dagger}$ Florian Diekmann, ${ }^{\dagger}$ Matthias Kalläne, ${ }^{\dagger}, \boldsymbol{\Phi}$ Torben Jasper-Toennies, ${ }^{\dagger}$ Axel \\ Buchholz, ${ }^{\S}$ Winfried Plass, ${ }^{\S}$ Richard Berndt, ${ }^{\dagger}$ Felix Tuczek, ${ }^{\ddagger}$ and Kai Rossnagel ${ }^{\dagger, \|,}, \mathbb{q}$ \\ $\dagger$ Institut für Experimentelle und Angewandte Physik, Christian-Albrechts-Universität zu \\ Kiel, 24098 Kiel, Germany \\ $\ddagger$ Institut für Anorganische Chemie, Christian-Albrechts-Universität zu Kiel, 24098 Kiel, \\ Germany \\ ฯ Ruprecht-Haensel-Labor, Christian-Albrechts-Universität zu Kiel und Deutsches \\ Elektronen-Synchrotron DESY, 24098 Kiel und 22607 Hamburg, Germany \\ $\S$ Institut für Anorganische und Analytische Chemie, Friedrich-Schiller-Universität, 07743 \\ Jena, Germany \\ ||Deutsches Elektronen-Synchrotron DESY, 22607 Hamburg, Germany
}

\begin{abstract}
Understanding and controlling the spin-crossover properties of molecular complexes can be of particular interest for potential applications in molecular spintronics. Using near edge X-ray absorption fine structure spectroscopy, we investigated these properties for a new vacuum-evaporable $\mathrm{Fe}(\mathrm{II})$ complex, namely $\mathrm{Fe}\left(\operatorname{pypyr}\left(\mathrm{CF}_{3}\right)_{2}\right)_{2}($ phen $)$ (pypyr $=2-(2$ 'pyridyl)pyrrolide, phen $=$ phenanthroline). We find that the spin-transition temperature, well above room temperature for the bulk compound, is drastically lowered for molecules arranged in thin films. Furthermore, while within the experimentally accessible temperature range $(2 \mathrm{~K}<T<410 \mathrm{~K})$ the bulk material shows neither indication of light-induced excited spin-state trapping (LIESST) nor indication of soft X-ray induced excited spin-state trapping (SOXIESST), these effects are observed for molecules within thin films up to temperatures around $100 \mathrm{~K}$. Thus, by arranging the molecules into thin films, a nominal low-spin complex is effectively transformed into a spin-crossover complex.
\end{abstract}

\section{Graphical TOC Entry}

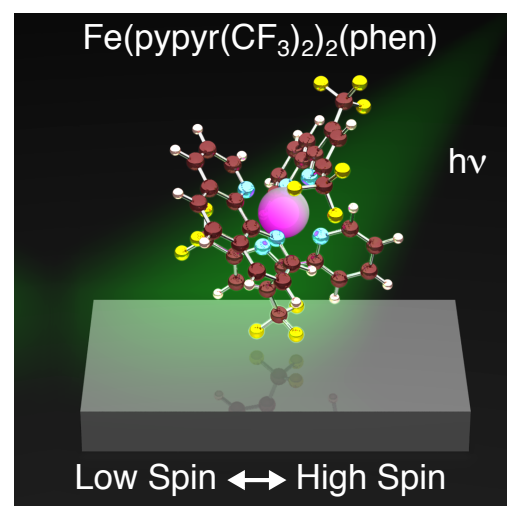

This document is the Accepted Manuscript version of a Published Work that appeared in final form in The Journal of Physical Chemistry Letters, copyright (c) American Chemical Society after peer review and technical editing by the publisher. To access the final edited and published work see https://www.doi.org/10.1021/acs.jpclett.8b00338. 
The emergence of new physical phenomena upon adsorption of molecules on surfaces has stimulated considerable research within the field of molecular spintronics. ${ }^{1-14}$ Conversely, for functional (e.g., switchable) molecules, the adsorption of such molecules on surfaces is often detrimental to their intrinsic functionality. ${ }^{15}$ Recently, substantial efforts focused on preventing or minimizing the so far unfavorable effect of the substrate on spin-crossover ( $\mathrm{SCO}$ ) complexes, a particular class of functional molecules, whose spin state can be switched by various stimuli including light. ${ }^{16}$ Indeed, the spin bistability or even the integrity of the fragile SCO complexes are generally affected by the proximity of metal surfaces. ${ }^{17-26}$ In such cases, the spinswitching functionality of the molecules may be restored by resorting to less reactive surfaces ${ }^{17,22-24,27-30}$ or by increasing the molecular-layer thickness, ${ }^{23,31-45}$ as the molecules are expected to gradually recover their intrinsic bulk properties as the layer thickness is increased. The reverse effect - SCO of a nominally nonswitching bulk compound enabled upon adsorption on a substrate - has so far not been reported. Here, we use near edge X-ray absorption fine structure (NEXAFS) spectroscopy to investigate the bulk and thinfilm SCO properties of a new vacuum-evaporable Fe(II) compound, namely $\mathrm{Fe}\left(\operatorname{pypyr}\left(\mathrm{CF}_{3}\right)_{2}\right)_{2}$ (phen) (pypyr = 2-(2'-pyridyl)pyrrolide, phen $=$ phenanthroline $)$, hereafter referred to as Fe-pypyr. Interestingly, the so-called light-induced spin-state trapping (LIESST), ${ }^{46-50}$ an effect common to SCO compounds where the spin state of the molecules is switched by light from a low-spin (LS) to a high-spin (HS) state at low temperature, is only observed in thin films. Furthermore, the spin-transition temperature is drastically reduced for the molecules within thin films relative to the bulk compound.

Fe-pypyr is composed of a $\mathrm{Fe}^{2+}$ ion surrounded by two 3,5-bis(trifluoromethyl)-2-(2'-pyridyl)pyrrolide ligands and by one phenanthroline ligand (Fig. 1a). From the fact that the pyrrolide groups of the two pypyr ligands are in trans position in the trigonal-bipyramidal precursor $\left[\mathrm{Fe}\left(\operatorname{pypyr}\left(\mathrm{CF}_{3}\right)_{2}\right)_{2}(\mathrm{THF})\right]$ (Ref. 51) we assume that this also holds for the title complex. The $\mathrm{C}_{2}$ symmetry of the complex is supported by the fact that the ${ }^{19} \mathrm{~F}$ NMR spectrum exhibits two signals of equal intensity for the $\mathrm{CF}_{3}$ groups of the pypyr ligands (see SI). The arrangement of the ligands leads to an octahedral nitrogen coordination around the Fe center. The resulting ligand field lifts the degeneracy of the five $d$ orbitals of the $\mathrm{Fe}$ ion into $\mathrm{e}_{\mathrm{g}}$ and $\mathrm{t}_{2 g}$ sets of orbitals (Fig. 1b). Depending on the strength of the ligand field, two electronic configurations of the Fe center can be realized, leading to two possible spin states. In the LS state, the six $d$ electrons of the Fe ion occupy the $t_{2 g}$ orbitals, forming a total spin $S=0$, while in the HS state, the $e_{g}$ and $t_{2 g}$ orbitals are partially filled resulting in a total spin $S=2$. A LS-to-HS transition may be achieved by increasing the temperature above the spin-transition temperature $T_{1 / 2}$, at which by definition $50 \%$ of the molecules are in the HS state. As will be discussed below, Fe-pypyr has a spin-transition temperature $T_{1 / 2}=390 \mathrm{~K}$, i.e., well above room temperature and is henceforth herein referred to as a nominal LS compound.

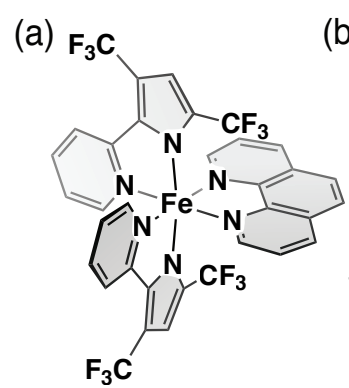

(b)

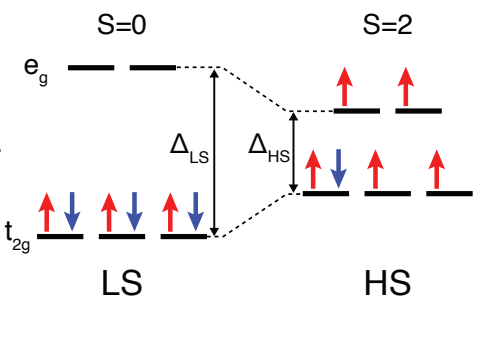

Figure 1: (a) Model of the Fe-pypyr molecule. (b) Simplified electronic configuration of the $\mathrm{Fe}^{2+}$ ion within Fe-pypyr. The total spin of the molecule depends on the strength of the ligand field and may be either $S=0$ (low spin) or $S=2$ (high spin).

NEXAFS spectroscopy provides chemical and orbital selectivity and thus is particularly suitable to determine the spin states of the investigated SCO molecules. In the present case, the $\mathrm{Fe} L_{2,3}$ absorption edges are of prime interest as their fine structure and energy position sensitively depend on the occupation and ligand field of the Fe $d$ orbitals. This leads to characteristic and distinct X-ray absorption (XA) spectra for the HS and LS states as previously reported for $\mathrm{Fe}^{2+}$-based $\mathrm{SCO}$ compounds. ${ }^{17,29,52-55}$

Figure 2a shows an XA spectrum at the Fe $L_{3}$ and $L_{2}$ edges for Fe-pypyr powder at $120 \mathrm{~K}$ (blue curve). As expected for a nominal LS compound, the XA spectrum is typical of that of a pure LS state. A second XA spectrum (red curve) was measured at $28 \mathrm{~K}$ under laser illumination. The light should switch the SCO molecules from the LS to a metastable HS state. For low temperatures (typically $<100 \mathrm{~K}$ ), the HS-to-LS relaxation can be sufficiently slow so that a fraction of the molecules effectively stays trapped in the HS state. The phenomenon is referred to as LIESST. ${ }^{46-50}$ Yet, the measured spectrum at $28 \mathrm{~K}$ (red curve in Figure 2a) is essentially the same as the one measured at $120 \mathrm{~K}$ (blue curve in Figure 2a), that is characteristic for a pure LS state. This implies that $T_{\text {LIESST }}$, which is here defined as the upper temperature at which the LIESST effect is visible, is lower than $28 \mathrm{~K}$.

It is worth mentioning that the signal-to-noise ratio of the X-ray spectra is reduced most probably due to charging ${ }^{56}$ of the molecules that affects the total electron yield signal. Furthermore, Fe impurities, most probably in the Ta foil used as a substrate for the powder, effectively broaden the spectra of Fe-pypyr powder (SI). Nevertheless, the quality of the spectra is sufficient to deduce the spin state of the investigated molecules. For comparison, the XA spectrum measured on the powder sample at $410 \mathrm{~K}$ with a HS proportion 
of approximately $90 \%$ is shown in Figure 2a (green). The different HS fractions in Fe-pypyr powder at $120 \mathrm{~K}$ $(0 \%)$ and at $410 \mathrm{~K}(90 \%)$ lead, as expected, to different XA spectra. Complementary SQUID measurements were carried out on Fe-pypyr powder (Figure 2c), not only confirming the NEXAFS results but also reducing the upper limit of $T_{\text {LIEss }}$ to $2 \mathrm{~K}$. Fe-pypyr powder is therefore effectively a LS compound with no evidence of the LIESST effect down to temperatures of $2 \mathrm{~K}$. As discussed below, the relaxation rate $k_{H S \rightarrow L S}$ is presumably too high for HS molecules to stay trapped.
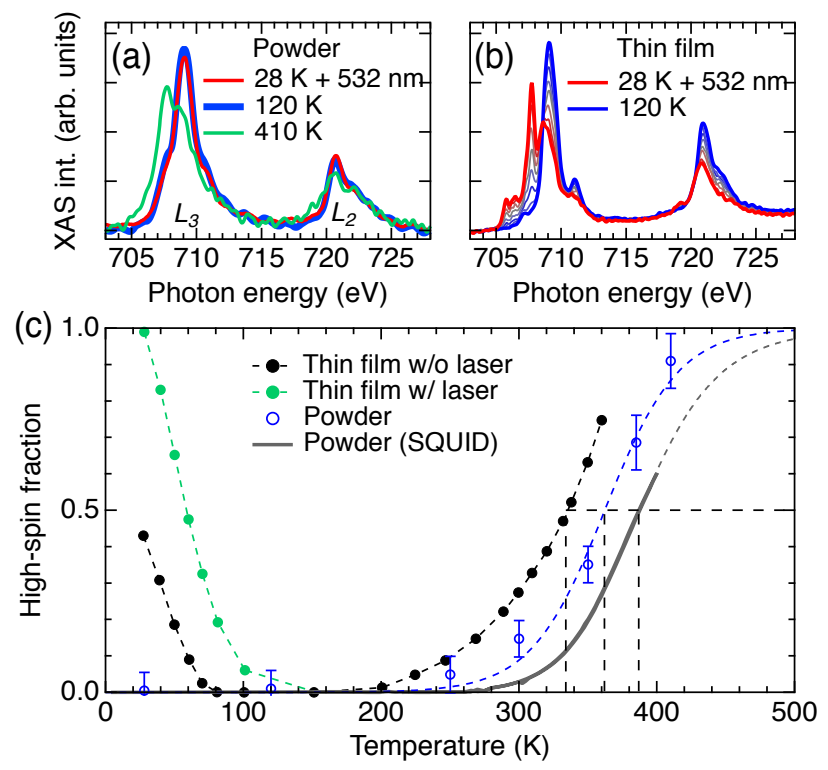

Figure 2: XA spectra at the Fe $L_{3}$ and $L_{2}$ edges for (a) an Fe-pypyr powder and (b) Fe-pypyr thin film $(\sim 40$ $\mathrm{ML})$ on $1 T-\mathrm{TiTe}_{2}$. The blue spectra were acquired at $120 \mathrm{~K}$ where the molecules are in the LS state. The red spectra were acquired at $28 \mathrm{~K}$ under illumination with a $532 \mathrm{~nm}$ laser (intensity of $1.6 \mathrm{~mW} \mathrm{~mm}^{-2}$ ). Only the Fe-pypyr molecules in the thin film exhibit switching to the HS state under illumination (same laser intensity). For comparison, a further XA spectrum acquired at $410 \mathrm{~K}$ (green, HS fraction of approximately $90 \%$ ) is displayed in (a). Additional XA spectra are shown in (b) for temperatures between $28 \mathrm{~K}$ and $120 \mathrm{~K}$ under illumination evidencing a gradual increase of the HS fraction. (c) Temperature dependence of the HS fractions for Fepypyr powder and Fe-pypyr thin film. The HS fraction is determined from XA spectra or from SQUID measurements (see SI), respectively. The Fe-pypyr thin film has a lower spin-transition temperature than the Fepypyr powder (black dashed lines). Furthermore, the Fe-pypyr thin film, in contrast to Fe-pypyr powder, exhibits a LS-to-HS transition at low temperatures via the SOXIESST and LIESST effects. The dashed gray line is an extrapolation of the SQUID measurement. The dashed blue, green and black lines are guides to the eye. The XA spectra shown in (a) have been smoothed.

$k_{H S \rightarrow L S}$ may be decreased provided that the (internal) pressure is reduced. ${ }^{50,57}$ While in bulk matrices this has been achieved by, e.g., Zn dilution, ${ }^{58}$ a reduction of the pressure can also be envisaged by reducing the dimensionality of the compound (e.g., in the form of thin films or nanoparticles). Indeed, previous studies reported (i) an anticorrelation between $T_{1 / 2}$ and $k_{H S \rightarrow L S}{ }^{50,57}$ and (ii) a tendency toward a reduced $T_{1 / 2}$ for SCO molecules in thin films or nanoparticles relative to the bulk form. ${ }^{35,44,59-61}$ This tendency can be rationalized by the correlation between $T_{1 / 2}$ and pressure. ${ }^{60,62-64}$ To decrease $k_{H S \rightarrow L S}$, we prepared thin films of Fe-pypyr (approximately $40 \mathrm{ML}$ ) on layered metallic $1 T-\mathrm{TiTe}_{2}{ }^{65}$ by thermal sublimation (see methods). Figure $2 \mathrm{~b}$ shows an XA spectrum at the Fe $L_{3}$ and $L_{2}$ edges for Fe-pypyr thin film at $120 \mathrm{~K}$ (blue curve). Again, the spectrum is characteristic of a pure LS state. Interestingly and in contrast to the powder sample, the XA data drastically change at $28 \mathrm{~K}$ under illumination with a $532 \mathrm{~nm}$ laser to the typical HS state spectrum (red curve). This demonstrates that illumination at $28 \mathrm{~K}$ switches the molecules from the LS to the HS state (LIESST effect). Note that the molecules progressively switch back to the LS state when the temperature is increased to $120 \mathrm{~K}$ (data not shown), evidencing the reversibility of the switching. From the change of the Fe XA spectrum from $120 \mathrm{~K}$ (blue) to $28 \mathrm{~K}$ (red), we infer that (i) the molecules are intact upon sublimation as they show a reversible switching behavior and (ii) $k_{H S \rightarrow L S}$ of Fe-pypyr is significantly decreased in thin film compared to the bulk form. XA spectra acquired at intermediate temperatures $(28 \mathrm{~K}<T<120 \mathrm{~K})$ under illumination (light blue and red curves in Figure 2b) show signatures common to the HS and LS XA spectra, which implies a coexistence of HS and LS molecules. The fraction of molecules in the HS state can be determined from the XA spectra as shown in the SI.

The HS fraction has been determined for different temperatures for Fe-pypyr powder and Fe-pypyr thin films (Figure 2c). On Fe-pypyr powder, spin-transition temperatures $T_{1 / 2}$ of $390 \mathrm{~K}$ and $360 \mathrm{~K}$ are inferred from SQUID and XA measurements, respectively. The difference is most probably due to the different ensembles of molecules probed by the two techniques. Indeed, while $\mathrm{XA}$ spectroscopy in total electron yield mode is surface sensitive and probes mostly the molecules at the surface of the crystallites (typical photoelectron escape depth on the order of $3 \mathrm{~nm}),{ }^{66}$ the HS fraction inferred from SQUID measurements is averaged over all molecules. In turn, this suggests a reduced $T_{1 / 2}$ (by $30 \mathrm{~K}$ or more) for the molecules at the surface of the crystallites relative to those in the core of the crystallites. At temperatures below $200 \mathrm{~K}$, the Fe-pypyr powder molecules are in the LS state (blue circles in Figure 2c) independent of illumination.

For Fe-pypyr thin films, the transition temperature $T_{1 / 2}$ is drastically reduced from $390 \mathrm{~K}$ to approximately $330 \mathrm{~K}$ (black dots in Figure 2c). This leaves approximately $25 \%$ of the molecules in the HS state at room temperature, in contrast to the almost pure LS state observed for Fe-pypyr powder. As shown above, Fe- 
pypyr thin films exhibit LIESST under illumination at $28 \mathrm{~K}$. In fact, the LIESST effect is visible up to temperatures around $100 \mathrm{~K}$ (green dots in Figure 2c). Furthermore, the LIESST effect is relatively efficient for the thin film of Fe-pypyr at $28 \mathrm{~K}$ where a HS fraction of $100 \%$ is reached. Note that the HS fractions reported in Figure 2c correspond to those of the stationary regime, where an equilibrium between excitation and relaxation is established under continuous illumination.

At low temperatures, Fe-pypyr thin films exhibit a non-negligible HS fraction without laser illumination (black dots in Figure 2c). This is due to the soft Xray induced excited spin-state trapping (SOXIESST) effect, where the LS-to-HS transition is driven by $\mathrm{X}$ rays. ${ }^{45,53,54}$

To check for possible substrate effects, we have performed similar measurements on Fe-pypyr thin films on layered semiconducting $1 T-\mathrm{HfS}_{2}$ (see supporting information (SI)). The values of $T_{1 / 2}$ and $T_{\text {LIESST }}$ are comparable to those of the Fe-pypyr $/ 1 T-\mathrm{TiTe}_{2}$ system, suggesting a limited influence of the substrate electronic properties on the SCO properties.

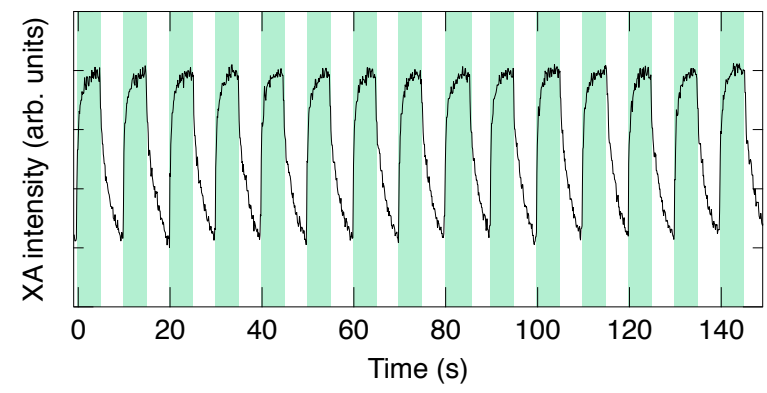

Figure 3: X-ray absorption intensity at a photon energy of $707.7 \mathrm{eV}$ from an Fe-pypyr thin film as a function of time at $28 \mathrm{~K}$. The sample is illuminated with a $532 \mathrm{~nm}$ laser for $5 \mathrm{~s}$ every $10 \mathrm{~s}$. The green areas correspond to the intervals with illumination. The XA intensity at a photon energy of $707.7 \mathrm{eV}$ is correlated to, but, due to photoelectric effects, not proportional to the HS fraction within the Fe-pypyr thin film. Nevertheless, the upper and lower HS fractions were determined from auxiliary XA spectra and are $95 \%$ and $85 \%$, respectively.

Above, we argued that the internal pressure exerted by the molecules is reduced when the molecules are arranged in a thin film, which in turn leads to a drastically decreased $k_{H S \rightarrow L S}$. In the following, we use the LIESST effect to estimate the excitation and relaxation rates $k_{H S \rightarrow L S}$ and $k_{L S \rightarrow H S}$, respectively. Figure 3 shows the evolution of the XA intensity on thin film Fe-pypyr at a photon energy of $707.7 \mathrm{eV}$ as a function of time with alternating cycles of illumination (532 nm laser on) and darkness (laser off). Since the XA spectrum of HS Fepypyr in the thin film exhibits a characteristic peak at a photon energy of $707.7 \mathrm{eV}$ (Figure 2b), the X-ray absorption intensity at this photon energy (displayed in
Figure 3) tracks the variation of the HS fraction. As expected for the LIESST effect, the XA intensity exponentially increases upon illumination and exponentially decreases in darkness. Furthermore, the minima and maxima of the XA intensity stay approximately constant over many cycles, evidencing the reproducibility of the LIESST effect. In addition, the data of Figure 3 indicate that no degradation of the investigated compound is noticeable over the duration of the experiment $(150 \mathrm{~s})$. In fact, radiation-induced damage of the Fe-pypyr molecules can be observed when the exposition to X-ray exceeds $30 \mathrm{~min}$ at a photon flux of $6 \times 10^{11} \mathrm{~s}^{-1} \mathrm{~cm}^{-2}$ (data not shown). To avoid radiation damage of the molecules, the X-ray spot on the sample was systematically displaced at the latest after $30 \mathrm{~min}$ and the photon flux reduced to $6 \times 10^{10} \mathrm{~s}^{-1} \mathrm{~cm}^{-2}$ for all measurements.

The time constants of the XA intensity rise and decay are in the range of seconds and can therefore be measured by XA with a typical acquisition time of $\approx 0.1 \mathrm{~s}$ per data point. At $28 \mathrm{~K}$, an excitation rate $k_{L S \rightarrow H S}$ on the order of $1 \mathrm{~s}^{-1}$ (under illumination with a $532 \mathrm{~nm}$ laser) and a relaxation rate of $k_{H S \rightarrow L S} \approx 3 \times 10^{-2} \mathrm{~s}^{-1}$ are extracted for Fe-pypyr in the thin film (see SI). Note that these rates are approximate because the SOXIESST effect concurrently takes place. The relaxation rates lie in the range usually observed for $\mathrm{Fe}^{2+}$-based SCO compounds. ${ }^{26,45,50,54,57}$ With the present experimental results, no HS-to-LS relaxation rate can be inferred for Fe-pypyr powder, because no LIESST effect was monitored. Nevertheless, relaxation rates between $10^{2} \mathrm{~s}^{-1}$ and $10^{6} \mathrm{~s}^{-1}$ were reported for SCO compounds with high spin-transition temperatures $\left(T_{1 / 2} \geq 370 \mathrm{~K}\right)$ or for pure LS compounds at low temperature. ${ }^{50,57}$ If one assumes such relaxation rates and an excitation rate identical to that of the Fe-pypyr thin films, a HS fraction $k_{L S \rightarrow H S} /\left(k_{L S \rightarrow H S}+k_{H S \rightarrow L S}\right)$ between $1 \%$ and $10^{-4} \%$ would be expected, i.e., well below or at the detection limit on Fe-pypyr powder (few percents). This confirms that no observable LIESST effect is expected on bulk Fepypyr samples, in agreement with the XA and SQUID data.

In conclusion, we have shown that by reducing the dimensionality (from bulk powder to thin films), the SCO properties of Fe-pypyr molecules are drastically modified: (i) the spin-transition temperature $T_{1 / 2}$ is reduced by approximately $60 \mathrm{~K}$, (ii) $T_{\text {LIESST }}$ is substantially increased, from below $2 \mathrm{~K}$ for powder to approximately $100 \mathrm{~K}$ for thin films, and (iii) the molecules become sensitive to the SOXIESST effect for temperatures between $28 \mathrm{~K}$ and approximately $90 \mathrm{~K}$. Therefore, by arranging the Fe-pypyr molecules into thin films, we transformed a nominal LS compound into a SCO material. The emergence of the SCO behavior is presumably caused by an effectively reduced internal pressure of the Fe-pypyr thin film relative to Fe-pypyr powder. These novel findings suggest a new strategy to achieve robust SCO molecules on surfaces. Considering that one of the main challenge in depositing SCO molecules on surfaces is their 
fragility, one may exploit (i) the usually increased robustness of the LS compound and (ii) the generation of the SCO properties of the nominal LS compound upon deposition on surfaces.

\section{Methods}

\section{Sample preparation}

$1 T-\mathrm{TiTe}_{2}$ is composed of covalently bonded Te-Ti-Te sandwich layers with weak van der Waals like forces between the triple layers. Atomically flat and chemically saturated surfaces were obtained by cleaving the crystals in vacuum along the basal plane. The Fe-pypyr molecules were deposited in ultra-high vacuum (base pressure of $5 \times 10^{-9}$ mbar) from a Knudsen cell heated at $160^{\circ} \mathrm{C}$ onto samples held at room temperature. The samples were then transferred to the analysis chamber without breaking the vacuum. The determination of the film thickness is based on the Fe $L_{3}$ edge jump by assuming $\sim 2 \%$ per ML. The relation between edge jump and thickness is inferred from auxiliary measurements on Fe-pypyr/Au(111) combining scanning tunneling microscopy and NEXAFS measurements. Furthermore, according to these measurements, the proportionality between edge jump and thickness seems to hold for this system for thicknesses in the range of $40 \mathrm{ML}$.

\section{X-ray absorption spectroscopy}

The XA spectroscopy measurements were performed at the P04 beamline ${ }^{67}$ at PETRA III (DESY, Hamburg). The X-ray beam was defocused (spot size of approximately $1.1 \mathrm{~mm} \times 1.1 \mathrm{~mm}$ ) and the photon flux reduced to $6 \times 10^{10} \mathrm{~s}^{-1} \mathrm{~cm}^{-2}$ to avoid noticeable damage of the molecules. The polarization of the X-rays was circular right. For the LIESST experiments, a $532 \mathrm{~nm}$ laser with an intensity of $1.6 \mathrm{~mW} \mathrm{~mm}^{-2}$ on the sample was used.

\section{Magnetic susceptibility}

Magnetic susceptibility data were obtained from powdered samples using a Quantum-Design MPMS-5 SQUID magnetometer equipped with a $5 \mathrm{~T}$ magnet. For the LIESST effect studies, a fiber optic sample holder (FOSH, Quantum Design) with a $200 \mathrm{~W} \mathrm{Hg}(\mathrm{Xe})$ arc lamp was used together with a filter wheel (filter centered at $510 \mathrm{~nm}$ with full width at half maximum of $80 \mathrm{~nm}$ ), shutter and a multicore fibre (all LOT Oriel). This light source is adequate for LIESST experiments on typical SCO complexes. ${ }^{68}$ Diamagnetic corrections were applied using the tabulated Pascal's constants.

Acknowledgement We acknowledge funding from the Deutsche Forschungsgemeinschaft (DFG) via Sonderforschungsbereich 677. Parts of this research were carried out at PETRA III at DESY, a member of the Helmholtz Association (HGF). We thank J. Buck, J. Seltmann, G. Hartmann, F. Scholz, J. Viefhaus for assistance in using the beamline P04.
Supporting Information Available: Additional information about the synthesis of Fe-pypyr, determination of the HS fraction, the excitation and relaxation rates and Fe-pypyr $/ \mathrm{HfS}_{2}$. This material is available free of charge via the Internet at http: //pubs.acs.org/.

Note: The authors declare no competing financial interest.

\section{References}

(1) Barraud, C.; Seneor, P.; Mattana, R.; Fusil, S.; Bouzehouane, K.; Deranlot, C.; Graziosi, P.; Hueso, L.; Bergenti, I.; Dediu, V. et al. Unravelling the Role of the Interface for Spin Injection Into Organic Semiconductors. Nat. Phys. 2010, 6, 615-620.

(2) Raman, K. V.; Kamerbeek, A. M.; Mukherjee, A.; Atodiresei, N.; Sen, T. K.; Lazić, P.; Caciuc, V.; Michel, R.; Stalke, D.; Mandal, S. K. et al. Interface-Engineered Templates for Molecular Spin Memory Devices. Nature 2013, 493, 509513.

(3) Djeghloul, F.; Ibrahim, F.; Cantoni, M.; Bowen, M.; Joly, L.; Boukari, S.; Ohresser, P.; Bertran, F.; Le Fèvre, P.; Thakur, P. et al. Direct Observation of a Highly Spin-Polarized Organic Spinterface at Room Temperature. Sci. Rep. 2013, 3, 1272.

(4) Steil, S.; Großmann, N.; Laux, M.; Ruffing, A.; Steil, D.; Wiesenmayer, M.; Mathias, S.; Monti, O. L. A.; Cinchetti, M.; Aeschlimann, M. SpinDependent Trapping of Electrons at Spinterfaces. Nat. Phys. 2013, 9, 242-247.

(5) Ma'Mari, F. A.; Moorsom, T.; Teobaldi, G.; Deacon, W.; Prokscha, T.; Luetkens, H.; Lee, S.; Sterbinsky, G. E.; Arena, D. A.; MacLaren, D. A. et al. Beating the Stoner Criterion Using Molecular Interfaces. Nature 2015, 524, 69-73.

(6) Barraud, C.; Bouzehouane, K.; Deranlot, C.; Fusil, S.; Jabbar, H.; Arabski, J.; Rakshit, R.; Kim, D.-J.; Kieber, C.; Boukari, S. et al. Unidirectional Spin-Dependent Molecule-Ferromagnet Hybridized States Anisotropy in Cobalt Phthalocyanine Based Magnetic Tunnel Junctions. Phys. Rev. Lett. 2015, 114, 206603.

(7) Gruber, M.; Ibrahim, F.; Boukari, S.; Isshiki, H.; Joly, L.; Peter, M.; Studniarek, M.; Da Costa, V.; Jabbar, H.; Davesne, V. et al. Exchange Bias and Room-Temperature Magnetic Order in Molecular Layers. Nat. Mater. 2015, 14, 981-984. 
(8) Bairagi, K.; Bellec, A.; Repain, V.; Chacon, C.; Girard, Y.; Garreau, Y.; Lagoute, J.; Rousset, S.; Breitwieser, R.; Hu, Y.-C. et al. Tuning the Magnetic Anisotropy at a Molecule-Metal Interface. Phys. Rev. Lett. 2015, 114, 247203.

(9) Gruber, M.; Ibrahim, F.; Boukari, S.; Joly, L.; Da Costa, V.; Studniarek, M.; Peter, M.; Isshiki, H.; Jabbar, H.; Davesne, V. et al. SpinDependent Hybridization between Molecule and Metal at Room Temperature through Interlayer Exchange Coupling. Nano Lett. 2015, 15, 79217926.

(10) Djeghloul, F.; Gruber, M.; Urbain, E.; Xenioti, D.; Joly, L.; Boukari, S.; Arabski, J.; Bulou, H.; Scheurer, F.; Bertran, F. et al. High Spin Polarization at Ferromagnetic Metal-Organic Interfaces: A Generic Property. J. Phys. Chem. Lett. 2016, 7, 2310-2315.

(11) Barraud, C.; Bouzehouane, K.; Deranlot, C.; Kim, D. J.; Rakshit, R.; Shi, S.; Arabski, J.; Bowen, M.; Beaurepaire, E.; Boukari, S. et al. Phthalocyanine Based Molecular Spintronic Devices. Dalton Trans. 2016, 45, 16694.

(12) Karan, S.; Li, N.; Zhang, Y.; He, Y.; Hong, I.-P.; Song, H.; Lü, J.-T.; Wang, Y.; Peng, L.; Wu, K. et al. Spin Manipulation by Creation of SingleMolecule Radical Cations. Phys. Rev. Lett. 2016, 116, 027201.

(13) Ma'Mari, F. A.; Rogers, M.; Alghamdi, S.; Moorsom, T.; Lee, S.; Prokscha, T.; Luetkens, H.; Valvidares, M.; Teobaldi, G.; Flokstra, M. et al. Emergent Magnetism at Transition-Metal-Nanocarbon Interfaces. Proc. Natl. Acad. Sci. 2017, 114, 55835588 .

(14) Studniarek, M.; Cherifi-Hertel, S.; Urbain, E.; Halisdemir, U.; Arras, R.; Taudul, B.; Schleicher, F.; Hervé, M.; Lambert, C.-H.; Hamadeh, A. et al. Modulating the Ferromagnet/Molecule Spin Hybridization Using an Artificial Magnetoelectric. Adv. Funct. Mater. 2017, 27, 1700259.

(15) Scheil, K.; Gopakumar, T. G.; Bahrenburg, J.; Temps, F.; Maurer, R. J.; Reuter, K.; Berndt, R. Switching of an Azobenzene-Tripod Molecule on Ag(111). J. Phys. Chem. Lett. 2016, 7, 2080-2084.

(16) Halcrow, M. A. Spin-Crossover Materials: Properties and Applications, 1st ed.; Wiley: Chichester, West Sussex, United Kingdom, 2013.

(17) Miyamachi, T.; Gruber, M.; Davesne, V.; Bowen, M.; Boukari, S.; Joly, L.; Scheurer, F.; Rogez, G.; Yamada, T. K.; Ohresser, P. et al. Robust Spin Crossover and Memristance Across a Single Molecule. Nat. Commun. 2012, 3, 938.
(18) Gopakumar, T. G.; Bernien, M.; Naggert, H.; Matino, F.; Hermanns, C. F.; Bannwarth, A.; Mühlenberend, S.; Krüger, A.; Krüger, D.; Nickel, F. et al. Spin-Crossover Complex on $\mathrm{Au}(111)$ : Structural and Electronic Differences Between Mono- And Multilayers. Chem. Eur. J. 2013, 19, 15702-15709.

(19) Gruber, M.; Davesne, V.; Bowen, M.; Boukari, S.; Beaurepaire, E.; Wulfhekel, W.; Miyamachi, T. Spin State of Spin-Crossover Complexes: From Single Molecules to Ultrathin Films. Phys. Rev. $B$ 2014, 89, 195415.

(20) Gueddida, S.; Gruber, M.; Miyamachi, T.; Beaurepaire, E.; Wulfhekel, W.; Alouani, M. Exchange Coupling of Spin-Crossover Molecules to Ferromagnetic Co Islands. J. Phys. Chem. Lett. 2016, 7, 900-904.

(21) Bairagi, K.; Iasco, O.; Bellec, A.; Kartsev, A.; Li, D.; Lagoute, J.; Chacon, C.; Girard, Y.; Rousset, S.; Miserque, F. et al. Molecular-Scale Dynamics of Light-Induced Spin Cross-Over in a Two-Dimensional Layer. Nat. Commun. 2016, 7, 12212 .

(22) Ossinger, S.; Naggert, H.; Kipgen, L.; JasperToennies, T.; Rai, A.; Rudnik, J.; Nickel, F.; Arruda, L. M.; Bernien, M.; Kuch, W. et al. VacuumEvaporable Spin-Crossover Complexes in Direct Contact With a Solid Surface: Bismuth Versus Gold. J. Phys. Chem. C 2017, 121, 1210-1219.

(23) Gruber, M.; Miyamachi, T.; Davesne, V.; Bowen, M.; Boukari, S.; Wulfhekel, W.; Alouani, M.; Beaurepaire, E. Spin Crossover in $\mathrm{Fe}(\text { phen })_{2}(\mathrm{NCS})_{2}$ Complexes on Metallic Surfaces. J. Chem. Phys. 2017, 146, 092312.

(24) Kuch, W.; Bernien, M. Controlling the Magnetism of Adsorbed Metal-organic Molecules. J. Phys.: Condens. Matter 2017, 29, 023001.

(25) Jasper-Tönnies, T.; Gruber, M.; Karan, S.; Jacob, H.; Tuczek, F.; Berndt, R. Deposition of a Cationic Fe $\mathrm{Fe}^{\mathrm{III}}$ Spin-Crossover Complex on $\mathrm{Au}(111)$ : Impact of the Counter Ion. J. Phys. Chem. Lett. 2017, 8, 1569-1573.

(26) Bairagi, K.; Bellec, A.; Fourmental, C.; Iasco, O.; Lagoute, J.; Chacon, C.; Girard, Y.; Rousset, S.; Choueikani, F.; Otero, E. et al. Temperature-, Light-, and Soft X-ray-Induced Spin Crossover in a Single Layer of $\mathrm{Fe}^{I I}$-Pyrazolylborate Molecules in Direct Contact with Gold. J. Phys. Chem. C 2017, 122, 727-731.

(27) Bernien, M.; Wiedemann, D.; Hermanns, C. F.; Krüger, A.; Rolf, D.; Kroener, W.; Müller, P.; Grohmann, A.; Kuch, W. Spin Crossover in a 
Vacuum-Deposited Submonolayer of a Molecular Iron(II) Complex. J. Phys. Chem. Lett. 2012, 3, 3431-3434.

(28) Gueddida, S.; Alouani, M. Spin Crossover in a Single Fe(phen $)_{2}(\mathrm{NCS})_{2}$ Molecule Adsorbed Onto Metallic Substrates: An Ab Initio Calculation. Phys. Rev. B 2013, 87, 144413.

(29) Bernien, M.; Naggert, H.; Arruda, L. M.; Kipgen, L.; Nickel, F.; Miguel, J.; Hermanns, C. F.; Krüger, A.; Krüger, D.; Schierle, E. et al. Highly Efficient Thermal and Light-Induced Spin-State Switching of an Fe(II) Complex in Direct Contact With a Solid Surface. ACS Nano 2015, 9, 8960-8966.

(30) Jasper-Toennies, T.; Gruber, M.; Karan, S.; Jacob, H.; Tuczek, F.; Berndt, R. Robust and Selective Switching of an $\mathrm{Fe}^{\mathrm{III}}$ Spin-Crossover Compound on $\mathrm{Cu}_{2} \mathrm{~N} / \mathrm{Cu}(100)$ with Memristance Behavior. Nano Lett. 2017, 17, 6613.

(31) Shi, S.; Schmerber, G.; Arabski, J.; Beaufrand, J.B.; Kim, D. J.; Boukari, S.; Bowen, M.; Kemp, N. T.; Viart, N.; Rogez, G. et al. Study of Molecular Spin-Crossover Complex $\mathrm{Fe}(\text { phen })_{2}(\mathrm{NCS})_{2}$ Thin Films. Appl. Phys. Lett. 2009, 95, 043303.

(32) Naggert, H.; Bannwarth, A.; Chemnitz, S.; von Hofe, T.; Quandt, E.; Tuczek, F. First Observation of Light-Induced Spin Change in Vacuum Deposited Thin Films of Iron Spin Crossover Complexes. Dalton Trans. 2011, 40, 6364-6366.

(33) Mahfoud, T.; Molnár, G.; Cobo, S.; Salmon, L.; Thibault, C.; Vieu, C.; Demont, P.; Bousseksou, A. Electrical Properties and Non-Volatile Memory Effect of the $\left[\mathrm{Fe}\left(\mathrm{HB}(\mathrm{pz})_{3}\right)_{2}\right]$ Spin Crossover Complex Integrated in a Microelectrode Device. Appl. Phys. Lett. 2011, 99, 053307.

(34) Gopakumar, T. G.; Matino, F.; Naggert, H.; Bannwarth, A.; Tuczek, F.; Berndt, R. ElectronInduced Spin Crossover of Single Molecules in a Bilayer on Gold. Angew. Chem., Int. Ed. 2012, 51, 6262-6266.

(35) Palamarciuc, T.; Oberg, J. C.; El Hallak, F.; Hirjibehedin, C. F.; Serri, M.; Heutz, S.; Létard, J. F.; Rosa, P. Spin Crossover Materials Evaporated Under Clean High Vacuum and Ultra-High Vacuum Conditions: From Thin Films to Single Molecules. J. Mater. Chem. 2012, 22, 9690-9695.

(36) Shepherd, H. J.; Molnár, G.; Nicolazzi, W.; Salmon, L.; Bousseksou, A. Spin Crossover at the Nanometre Scale. Eur. J. Inorg. Chem. 2012, 2013, 653-661.
(37) Warner, B.; Oberg, J. C.; Gill, T. G.; El Hallak, F.; Hirjibehedin, C. F.; Serri, M.; Heutz, S.; Arrio, M.A.; Sainctavit, P.; Mannini, M. et al. TemperatureAnd Light-Induced Spin Crossover Observed by XRay Spectroscopy on Isolated Fe(II) Complexes on Gold. J. Phys. Chem. Lett. 2013, 4, 1546-1552.

(38) Pronschinske, A.; Chen, Y.; Lewis, G. F.; Shultz, D. A.; Calzolari, A.; Buongiorno Nardelli, M.; Dougherty, D. B. Modification of Molecular Spin Crossover in Ultrathin Films. Nano Lett. 2013, 13, 1429-1434.

(39) Pronschinske, A.; Bruce, R. C.; Lewis, G.; Chen, Y.; Calzolari, A.; Buongiorno-Nardelli, M.; Shultz, D. A.; You, W.; Dougherty, D. B. Iron(II) Spin Crossover Films on $\mathrm{Au}(111)$ : Scanning Probe Microscopy and Photoelectron Spectroscopy. Chem. Commun. 2013, 49, 1044610452 .

(40) Ludwig, E.; Naggert, H.; Kalläne, M.; Rohlf, S.; Kröger, E.; Bannwarth, A.; Quer, A.; Rossnagel, K.; Kipp, L.; Tuczek, F. Iron(II) SpinCrossover Complexes in Ultrathin Films: Electronic Structure and Spin-State Switching by Visible and Vacuum-UV Light. Angew. Chem., Int. Ed. 2014, 53, 3019-3023.

(41) Molnár, G.; Salmon, L.; Nicolazzi, W.; Terki, F.; Bousseksou, A. Emerging Properties and Applications of Spin Crossover Nanomaterials. J. Mater. Chem. C 2014, 2, 1360.

(42) Davesne, V.; Gruber, M.; Studniarek, M.; Doh, W. H.; Zafeiratos, S.; Joly, F., L. Sirotti; Silly, M. G.; Gaspar, A. B.; Real, J. A.; Schmerber, G. et al. Hysteresis and Change of Transition Temperature in Thin Films of Fe[Me $\left[\mathrm{Me}_{2} \mathrm{Pyz}\right]_{3} \mathrm{BH}_{2}$, a New Sublimable Spin-Crossover Molecule. J. Chem. Phys. 2015, 142, 194702.

(43) Lefter, C.; Davesne, V.; Salmon, L.; Molnár, G.; Demont, P.; Rotaru, A.; Bousseksou, A. Charge Transport and Electrical Properties of Spin Crossover Materials: Towards Nanoelectronic and Spintronic Devices. Magnetochemistry 2016, 2, 18.

(44) Iasco, O.; Boillot, M.-L.; Bellec, A.; Guillot, R.; Rivière, E.; Mazerat, S.; Nowak, S.; Morineau, D.; Brosseau, A.; Miserque, F. et al. The Disentangling of Hysteretic Spin Transition, Polymorphism and Metastability in Bistable Thin Films Formed by Sublimation of bis(scorpionate) Fe(II) Molecules. J. Mater. Chem. C 2017, 5, 11067.

(45) Kipgen, L.; Bernien, M.; Nickel, F.; Naggert, H.; Britton, A. J.; Arruda, L. M.; Schierle, E.; Weschke, E.; Tuczek, F.; Kuch, W. Soft-X-RayInduced Spin-State Switching of an Adsorbed 
Fe(II) Spin-Crossover Complex. J. Phys.: Condens. Matter 2017, 29, 394003.

(46) Decurtins, S.; Gütlich, P.; Köhler, C. P.; Spiering, H.; Hauser, A. Light-Induced Excited Spin State Trapping in a Transition-Metal Complex: the hexa-1-propyltetrazole-iron(II) tetrafluoroborate Spin-Crossover System. Chem. Phys. Lett. 1984, 105, 1-4.

(47) Adler, P.; Spiering, H.; Guetlich, P. Investigation of the ${ }^{1} \mathrm{~A}_{1} \rightarrow{ }^{5} \mathrm{~T}_{2}$ Intersystem Crossing Dynamics of an Iron(II) Spin-Crossover Complex in the Solid State by Moessbauer Spectroscopy. Inorg. Chem. 1987, 26, 3840-3845.

(48) Hauser, A.; Vef, A.; Adler, P. Intersystem Crossing Dynamics in $\mathrm{Fe}(\mathrm{II})$ Coordination Compounds. $J$. Chem. Phys. 1991, 95, 8710-8717.

(49) Létard, J.-F.; Capes, L.; Chastanet, G.; Moliner, N.; Létard, S.; Real, J.-A.; Kahn, O. Critical Temperature of the LIESST Effect in Iron(II) Spin Crossover Compounds. Chem. Phys. Lett. 1999, 313, 115-120.

(50) Hauser, A. Spin Crossover in Transition Metal Compounds II; Topics in Current Chemistry 234; Springer Berlin Heidelberg, 2004; pp 155-198.

(51) Searles, K.; Das, A. K.; Buell, R. W.; Pink, M.; Chen, C.-H.; Pal, K.; Morgan, D. G.; Mindiola, D. J.; Caulton, K. G. 2,2'-Pyridylpyrrolide Ligand Redistribution Following Reduction. Inorg. Chem. 2013, 52, 5611-5619.

(52) Cartier dit Moulin, C.; Rudolf, P.; Flank, A. M.; Chen, C. T. Spin Transition Evidenced by Soft X-Ray Absorption Spectroscopy. J. Phys. Chem. 1992, 96, 6196-6198.

(53) Collison, D.; Garner, C. D.; McGrath, C. M.; Mosselmans, J. F. W.; Roper, M. D.; Seddon, J. M. W.; Sinn, E.; Young, N. A. Soft X-Ray Induced Excited Spin State Trapping and Soft XRay Photochemistry at the Iron $\mathrm{L}_{2,3}$ Edge in $\left[\mathrm{Fe}(\text { phen })_{2}(\mathrm{NCS})_{2}\right]$ and $\left[\mathrm{Fe}(\text { phen })_{2}(\mathrm{NCSe})_{2}\right]$ (phen = 1,10-phenanthroline). Dalton Trans. 1997, 4371-4376.

(54) Davesne, V.; Gruber, M.; Miyamachi, T.; Da Costa, V.; Boukari, S.; Scheurer, F.; Joly, L.; Ohresser, P.; Otero, E.; Choueikani, F. et al. First Glimpse of the Soft X-Ray Induced Excited Spin-State Trapping Effect Dynamics on Spin Cross-Over Molecules. J. Chem. Phys. 2013, 139, 074708.

(55) Kumar, K. S.; Studniarek, M.; Heinrich, B.; Arabski, J.; Schmerber, G.; Bowen, M.; Boukari, S.;
Beaurepaire, E.; Dreiser, J.; Ruben, M. Engineering On-Surface Spin Crossover: Spin-State Switching in a Self-Assembled Film of VacuumSublimable Functional Molecule. Adv. Mater. 2018, 1705416.

(56) Vlachos, D.; Craven, A. J.; McComb, D. W. Specimen Charging in X-Ray Absorption Spectroscopy: Correction of Total Electron Yield Data from Stabilized Zirconia in the Energy Range 250-915 eV. J. Synchrotron Radiat. 2005, 12, 224-233.

(57) Gütlich, P.; Hauser, A.; Spiering, H. Thermal and Optical Switching of Iron (II) Complexes. Angew. Chem. Int. Ed. 1994, 33, 2024-2054.

(58) Hauser, A.; Enachescu, C.; Daku, M. L.; Vargas, A.; Amstutz, N. Low-Temperature Lifetimes of Metastable High-Spin States in Spin-Crossover and in Low-Spin Iron(II) Compounds: The Rule and Exceptions to the Rule. Coord. Chem. Rev. 2006, 250, 1642-1652.

(59) Félix, G.; Nicolazzi, W.; Salmon, L.; Molnár, G.; Perrier, M.; Maurin, G.; Larionova, J.; Long, J.; Guari, Y.; Bousseksou, A. Enhanced Cooperative Interactions at the Nanoscale in Spin-Crossover Materials with a First-Order Phase Transition. Phys. Rev. Lett. 2013, 110, 235701.

(60) Mikolasek, M.; Félix, G.; Nicolazzi, W.; Molnár, G.; Salmon, L.; Bousseksou, A. Finite Size Effects in Molecular Spin Crossover Materials. New J. Chem. 2014, 38, 1834-1839.

(61) Molnár, G.; Rat, S.; Salmon, L.; Nicolazzi, W.; Bousseksou, A. Spin Crossover Nanomaterials: From Fundamental Concepts to Devices. Adv. Mater. 2017, 17003862.

(62) Ksenofontov, V.; Levchenko, G.; Spiering, H.; Gütlich, P.; Létard, J.-F.; Bouhedja, Y.; Kahn, O. Spin Crossover Behavior under Pressure of $\mathrm{Fe}(\mathrm{PM}-\mathrm{L})_{2}(\mathrm{NCS})_{2}$ Compounds with Substituted 2'-pyridylmethylene 4-anilino Ligands. Chem. Phys. Lett. 1998, 294, 545-553.

(63) Bousseksou, A.; Molnár, G.; Tuchagues, J. P.; Menéndez, N.; Codjovi, É.; Varret, F. Triggering the Spin-Crossover of Fe(phen $)_{2}$ (NCS $)_{2}$ by a Pressure Pulse. Pressure and Magnetic Field Induce mirror effects. C. R. Chim. 2003, 6, 329-335.

(64) Ksenofontov, V.; Gaspar, A. B.; Gütlich, P. Spin Crossover in Transition Metal Compounds III; Topics in Current Chemistry 235; Springer Berlin Heidelberg, 2004; pp 23-64.

(65) Rossnagel, K.; Kipp, L.; Skibowski, M.; Solterbeck, C.; Strasser, T.; Schattke, W.; Voß, D.; 
Krüger, P.; Mazur, A.; Pollmann, J. ThreeDimensional Fermi Surface Determination by Angle-Resolved Photoelectron Spectroscopy. Phys. Rev. B 2001, 63, 125104.

(66) Stöhr, J. Nexafs Spectroscopy; Springer; Springer Series in Surface Sciences, 1996.

(67) Viefhaus, J.; Scholz, F.; Deinert, S.; Glaser, L.; Ilchen, M.; Seltmann, J.; Walter, P.; Siewert, F. The Variable Polarization XUV Beamline P04 at PETRA III: Optics, mechanics and their performance. Nucl. Instrum. Methods Phys. Res. A 2013, 710, 151-154.

(68) Schmidt, S. O.; Naggert, H.; Buchholz, A.; Brandenburg, H.; Bannwarth, A.; Plass, W.; Tuczek, F. Thermal and Light-Induced Spin Transitions of FeII Complexes with 4- and 5-(Phenylazo)-2,2'bipyridine Ligands: Intra- vs. Intermolecular Effects. Eur. J. Inorg. Chem. 2016, 2016, 21752186 . 